\title{
C,N-CHELATED CARBENE COMPLEXES \\ OF PALLADIUM(II) AS POTENTIAL PHARMACOLOGICALLY ACTIVE COMPOUNDS
}

\author{
V. Boyarsky', A. Mikherdov', S. Baikov', P. Savko', R. Suezov² \\ and R. Trifonov ${ }^{1}$ \\ ${ }^{1}$ Institute of Chemistry, St. Petersburg State University, \\ 199034, Russia, St. Petersburg, Universitetskaya nab., 7/9. \\ ${ }^{2}$ Institute of Cytology RAS, 199064, Russia, St. Petersburg, Tikhoretsky pr., 4.
}

DOI: 10.19163/MedChemRussia2021-2021-50

E-mail:v.boiarskii@spbu.ru

It is known that complexes of transition metals with $\mathrm{N}$-heterocyclic carbene ligands (NHC) possess a number of unique properties, including antibacterial, antifungal and antitumor activity. The properties of related complexes with acyclic diaminocarbene ligands (ADC) have been much less studied. However, such compounds can be expected to exhibit pharmacological activity as well. Indeed, we have recently shown that platinum and palladium complexes with ADCs based on benzenediamines possess some antitumor activity.

Complexes of platinum metal ions with ADCs, which also contain a heterocyclic moiety, seem to be especially promising for biomedicine. In this regard, palladium complexes are of the greatest interest, since the use of platinum drugs for cancer chemotherapy is limited by side effects associated with low selectivity towards healthy cells and the presence of a large number of cancer cell lines resistant to their action. Therefore, we focused our efforts on the synthesis of the palladium derivatives. In this case, the reaction of bis (isocyanide) complexes of $\mathrm{Pd}(\mathrm{II})$ with amino azaheterocycles is used as a synthesis method. Previously, using this reaction, we synthesized several series of diaminocarbene complexes of platinum group metals containing aminoheterocyclic fragments, but their cytotoxic activity has not been studied.

In this work, new diaminocarbene complexes of $\mathrm{Pd}(\mathrm{II})$ containing 2-aminothiazole and 2-aminobenzoxazole heterocyclic fragments were synthesized by the interaction of cis- $\left[\mathrm{PdCl}_{2}(\mathrm{CNCy})_{2}\right]$ with 2-aminobenzoxazole and a number of substituted 2-aminothiazoles. The cytotoxicity of the synthesized diaminocarbene $\mathrm{Pd}(\mathrm{II})$ complexes was studied against human cancer cells MCF7, HL60, HeLa, DLD1, A431.

Acknowledgment: The work was supported by the grant from the Russian Science

Foundation No. 19-13-00008. 